\title{
Persistent annual migration patterns of a specialist seabird
}

\author{
Rachael A. Orben ${ }^{1, *}$, Nobuo Kokubun ${ }^{2}$, Abram B. Fleishman ${ }^{3,4}$, Alexis P. Will ${ }^{2,5}$, \\ Takashi Yamamoto ${ }^{2,6}$, Scott A. Shaffer ${ }^{3}$, Rosana Paredes ${ }^{7}$, Akinori Takahashi ${ }^{2}$, \\ Alexander S. Kitaysky ${ }^{5}$ \\ ${ }^{1}$ Department of Fisheries and Wildlife, Oregon State University, Hatfield Marine Science Center, 2030 SE Marine Science Dr., \\ Newport, OR 97365, USA \\ ${ }^{2}$ National Institute of Polar Research, Tachikawa, Tokyo 190-8518, Japan \\ ${ }^{3}$ Department of Biological Sciences, San Jose State University, One Washington Square, San Jose, CA 95192-0100, USA \\ ${ }^{4}$ Conservation Metrics, Inc., 145 McAlister Way, Santa Cruz, CA 95060, USA \\ ${ }^{5}$ Department of Biology and Wildlife, Institute of Arctic Biology, University of Alaska Fairbanks, Fairbanks, \\ AK 99775-7000, USA \\ ${ }^{6}$ Graduate School of Environmental Studies, Nagoya University, Nagoya, Aichi 464-8601, Japan \\ ${ }^{7}$ Department of Fisheries and Wildlife, 104 Nash Hall, Oregon State University, Corvallis, OR 97331-3803, USA
}

\begin{abstract}
Specialization can make animals vulnerable to rapid environmental changes. For longlived seabirds, foraging specialization may make individuals especially sensitive, as climatic changes are currently occurring over the course of one lifetime. The Bering Sea is a dynamic subarctic and arctic ecosystem where windblown sea ice mediates annual productivity and subsequent pathways to upper trophic levels. Red-legged kittiwakes Rissa brevirostris are endemic surface foraging seabirds specializing on myctophid fishes during reproduction. Their degree of specialization outside the breeding season is less understood. We examined their non-breeding ecology (migration, distribution, isotopic niche) during 4 winters with varying sea ice extent. Although we found annual variation in core distributions, diets (as reflected in feather stable isotope signatures), and outbound migratory timing, the winter range of red-legged kittiwakes was restricted to the western regions of the Bering Sea and North Pacific. Contrary to expectations, sea ice did not limit distributions in the Bering Sea in 3 yr: e.g. sea ice associations $(<100 \mathrm{~km})$ were infrequent $\left(8.7 \% \mathrm{mo}^{-1}\right)$. Yet, their wintering range often overlapped with areas of seasonal ice cover, suggesting range-wide use of sea ice ecosystems. Stress levels measured by corticosterone in feathers were generally low. However, birds that concentrated in the Bering Sea in February had higher stress levels and fed at a lower trophic level than those in the western Aleutians and western subarctic. As conditions change, this persistence in wintering locations, while incurring differential stress levels, may contribute to rapid population fluctuations as has been observed in the recent past.
\end{abstract}

KEY WORDS: Feather corticosterone - Life-history trade-off - Geolocation - Migration · Net-squared displacement $\cdot$ Stable isotopes $\cdot$ Red-legged kittiwake $\cdot$ Rissa brevirostris

\section{INTRODUCTION}

Specialization in habitat use, diet, or behavior can make animals vulnerable to rapid environmental changes (Colles et al. 2009, Clavel et al. 2011). If spe-

*Corresponding author: raorben@gmail.com cialists are long-lived animals, they may be particularly vulnerable to anthropogenically driven climate change, as individuals are now experiencing significant environmental changes over the course of their lifetime (Henson et al. 2017). Specialization can occur restricted. Authors and original publication must be credited. 
at individual, population, and species levels. The degree of specialization can be considered on a continuum (Bolnick et al. 2003). For instance, foraging strategies and habitat are often linked, and this may result in seasonal or annual variation in diet (e.g. Hückstädt et al. 2012). Yet, within a season, individuals may continually specialize on the same prey (Elliott et al. 2009). Conceivably, narrow dietary preferences for certain prey could limit foraging in the midst of what appear to be ample resources. Specialization can occur in tandem with flexibility in other behaviors, such as the ability to adjust breeding or migratory phenology. Understanding how individuals of specialized populations alter or maintain migratory behavior in the face of differing annual conditions may help to further our understanding of how they might fare under future climatic conditions.

Foraging or migratory specialists are presumed to be employing a predictably beneficial strategy, yet changing conditions could alter the cost of strategies over both the short and long term. In seabirds, including red-legged kittiwakes Rissa brevirostris, the stress hormone corticosterone can be used as a proxy to measure relative exposure to nutritional stress (Kitaysky et al. 2001, 2007) and provides a mechanistic link between food shortages and reproductive timing, success, and survival (Goutte et al. 2011, Nelson et al. 2015). Furthermore, corticosterone is incorporated into feathers, providing an integrated measure of the nutritional stress experienced during feather growth (Bortolotti et al. 2008, Will et al. 2014). Therefore, feathers can be collected during the breeding season and provide insight into the nutritional history of a bird's preceding migration that can be related to concurrent tracking data. The combination of spatial and physiological information allows for a representation of the 'stress landscape' experienced by individuals during the molting period.

The Bering Sea is a dynamic marine ecosystem situated at the boundary of the subarctic and arctic biomes, and in recent years anthropogenic climate change has driven changes in environmental conditions and dependent ecosystem components (Grebmeier et al. 2006, Litzow et al. 2014, Springer \& van Vliet 2014). The eastern Bering Sea is dominated by a shallow shelf that in some years is covered by windblown sea ice (Brown et al. 2011). Running the south-north length of the Bering Sea, the shelf break is often termed the 'Green Belt' for its high productivity (Springer et al. 1996). Likewise, the narrow shelf in the western Bering Sea is associated with high productivity (Brown et al. 2011, Belkin 2016). In contrast, the northern arctic portion of the Bering Sea is supported by benthic-based food webs (Grebmeier et al. 2006). Framed by these shelf ecosystems, the Bering Sea basin is dominated by an anticyclonic current and eddies that concentrate prey for seabirds and seals (Nordstrom et al. 2013, Paredes et al. 2014). In the eastern Bering Sea, the duration, timing, and extent of sea ice over the shelf interact to influence primary productivity, and distributions of upper trophic organisms such as fish and seabirds (WyllieEcheverria \& Wooster 1998, Renner et al. 2016). The relationship between sea ice and species that primarily use the waters of the Bering Sea basin is less understood. The contemporary Bering Sea, particularly the eastern shelf region, oscillates between years dominated by warmer water temperatures and less sea ice, contrasted by years of colder temperatures (Overland et al. 2012). In simple terms, these oscillations provide a natural experiment for how long-lived upper trophic level organisms may react to fundamental changes in prey type and availability that occur with annual changes in sea ice extent.

Red-legged kittiwakes are surface-foraging seabirds endemic to the Bering Sea, nesting at only a few colonies along the Aleutian Islands, in the Commander Islands, and in the Pribilof Islands, where $>70 \%$ of the entire population nests on the tall cliffs of St. George Island ( 235 000 pairs; Byrd et al. 2008a, Goyert et al. 2017). Red-legged kittiwake populations at St. George Island experienced a significant decline in the 1980s leading to an IUCN 'Vulnerable' designation (BirdLife International 2017). In summer, red-legged kittiwakes are more specialized in diet and habitat use than their congener, the blacklegged kittiwake $R$. tridactyla, foraging almost exclusively (by volume) on myctophid fishes and squid that are found at the surface at night in waters over the slope and basin (Sinclair et al. 2008, Kokubun et al. 2015). Both kittiwakes breeding on St. George Island have similar overall productivity (fledglings nest $^{-1}$ ), but red-legged kittiwakes typically have higher fledgling success (chicks fledged per number of eggs laid) than black-legged kittiwakes (Byrd et al. 2008b, Springer \& van Vliet 2014), providing evidence that they are employing a foraging strategy that is usually profitable.

Although foraging specialization of red-legged kittiwakes in the breeding season is well documented, little is known about their specialization during nonbreeding. In comparison to black-legged kittiwakes, red-legged kittiwakes have a narrower dietary niche (quantified by stable isotope values of feathers) and occupy a substantially smaller wintering range, both as a group and individually (Orben et al. 2015a). 
However, these earlier results were based on a single winter of tracking, and distributions could shift annually (Orben et al. 2015b). Red-legged kittiwake tracking data and at-sea observations indicate the use of shelf habitats in both the northern and eastern Bering Sea, where their summer prey are not typically found (Tanimata et al. 2005), which suggests seasonal dietary flexibility. Additionally, the use of the northern Bering Sea during the autumn suggests the potential for sea ice-associated foraging, although due to the coarseness of geolocation tracking data, the exact degree of fine-scale spatial overlap is unknown (e.g. roosting, foraging in leads, avoidance; Orben et al. 2015a). Regardless, tracking individual movements across multiple years with differing sea ice conditions could help disentangle the degree to which red-legged kittiwakes are consistently associated with sea ice at broad spatial scales. Multiple years of tracking data will also further our understanding of the extent that red-legged kittiwakes are restricted in range during the winter, potentially a form of spatial or habitat specialization, and the degree to which migration timing is consistent. Feather stable isotopes can provide evidence for dietary specialization, in terms of similarity between individuals, during the period of feather growth (Thompson \& Furness 1995). For red-legged kittiwakes, the period just before the birds return to the colony region could be expected to correspond to a period of food shortages when winter food resources are depleted and prior to the onset of spring productivity. This is also when birds undergo costs of growing feathers during their prenuptial molt and may need to regain/maintain body condition in preparation for breeding. Thus, this is a key time period during which to assess nutritional stress experienced during migration.

We tracked red-legged kittiwakes with geolocation data loggers during 4 winter migrations with variable sea ice conditions to better understand the degree to which these birds can be considered populationlevel migratory specialists during this timeframe. Given their consistency in foraging behavior during breeding, we predicted that specialization during the remainder of the year would also be apparent. The aims of our study were as follows: (1) to quantify between individual and among-year variation in wintering distributions, stable isotope inferred niches, and migratory timing; $(2)$ to evaluate whether redlegged kittiwakes are consistently associated with sea ice at a broad scale; and (3) to test if differences in habitat use and migratory behavior correspond to winter stress levels, and if there is spatial structure in these values. These results provide the first look at changes in wintering behavior over a relatively long period (albeit still a short-term time period for this long-lived seabird).

\section{MATERIALS AND METHODS}

To study red-legged kittiwake wintering ecology, geolocation loggers that record light and wet/dry data were deployed on 96 red-legged kittiwakes in 2010 (Mk9, Mk19, British Antarctic Survey), 2013 and 2014 (Mk3, Biotrack), and 2015 (C-65, Migrate Technology) at St. George Island (56 $\left.36^{\prime} \mathrm{N}, 169^{\circ} 33^{\prime} \mathrm{W}\right)$ in the Pribilof Islands, Alaska, USA (Table 1). In successive years, $72 \%$ of birds were recaptured, and 59 complete wintering trips were obtained (Table 1). Loggers were attached to plastic leg bands using zip-ties and weighed 1-2.5 g. Although we cannot discount tagging effects, all loggers represented $0.2-0.8 \%$ of the birds' body weight $(\mathrm{n}=107 ; 375 \pm$ $29[\mathrm{SD}] \mathrm{g}, \mathrm{min} .=305 \mathrm{~g}, \max .=470 \mathrm{~g})$, a percentage below that at which minor negative effects have been recorded for smaller-bodied seabirds (Quillfeldt et al. 2012). Birds were caught at their nest sites using

Table 1. Sample sizes of red-legged kittiwakes deployed and retrieved with geolocation loggers from St. George Island, Alaska, USA. In total, 59 complete wintering trips were recorded (1 September to 15 April). In all years, additional birds were seen but not recaptured. Higher recapture rates in 2013-2014 and 2014-2015 are due to 3 and 2 yr of recapture effort, respectively. Only 1 yr of recapture effort occurred for the 2010-2011 birds

\begin{tabular}{|c|c|c|c|c|c|c|c|c|}
\hline 2010-2011 & Mk9/Mk19 & 2.5 & 23 & 16 & 15 & 69.6 & 6.3 & 65.2 \\
\hline 2013-2014 & Mk3 & 2.5 & 19 & 16 & 12 & 84.2 & 25 & 63.1 \\
\hline 2014-2015 & Mk3 & 2.5 & 20 & 14 & 9 & 70.0 & 35.7 & 45 \\
\hline 2015-2016 & C-65 & 1 & 34 & 23 & 23 & 67.6 & 0 & 67.6 \\
\hline
\end{tabular}


noose poles, foot snares, or a handheld $\mathrm{CO}_{2}$ powered net gun (2011 recaptures only; Super Talon Animal Catcher; Advanced Weapons Technology). Head feathers (side of head), grown during the pre-nuptial molt from February to March (Gabrielson \& Lincoln 1959), were collected at recapture.

\section{Geolocation processing}

To estimate locations, we first identified the timing of twilight associated with sunrise and sunset, and then twilight estimations were automatically selected (github.com/slisovski/twGeos). We used a light threshold of 0.5 for all tracks, but adjusted the sun angle selection window for each tag type to reduce the north-south spread of points (Mk19: -3 to 0 ; Mk9: -5 to $0, \mathrm{Mk3}$ : -6 to 0 ; C-65: -7 to -1 ). Tracks were estimated using an iterative forward step selection process by computing the weighted probability for a cloud of possible locations (number of particles at each time step $=10000$ ) and selecting a potential location (Merkel et al. 2016). To calculate a median geographic track, this process was iterated along the track for 200 iterations (Merkel et al. 2016). A land mask $\left(0.25^{\circ} \times 0.25^{\circ}\right.$, NOAA OI SST V2 High Resolution Dataset) prevented the selection of points on land; however, this did not prohibit tracks from crossing land, particularly the Kamchatka $(\mathrm{n}=14)$ and Alaska Peninsulas $(n=3)$, which are narrow enough for a kittiwake to cross in one $12 \mathrm{~h}$ period. Estimated travel speed of each individual was included for dry (in flight) $\left(\max =22.22 \mathrm{~m} \mathrm{~s}^{-1}\right.$, mean $\pm \mathrm{SD}=10.6 \pm$ $5.3 \mathrm{~m} \mathrm{~s}^{-1}$; Paredes et al. 2012, Elliott et al. 2014) and wet (on water) $\left(\max =1.7 \mathrm{~m} \mathrm{~s}^{-1}, \mathrm{SD}=0.25 \mathrm{~m} \mathrm{~s}^{-1}\right.$, optimal $=0.5 \mathrm{~m} \mathrm{~s}^{-1}$; Conners et al. 2015) activity bins. Double tagging with GPS data loggers indicates that a median error in locations associated with this method (calculated at similar latitudes) is $185 \mathrm{~km}$ for the solstice and $145 \mathrm{~km}$ for equinox periods (Merkel et al. 2016). Two individuals were tracked for 2 complete consecutive winters; however, as black-legged kittiwakes show some site fidelity in their winter migrations (Orben et al. 2015b), and this appears to be the case for red-legged kittiwakes as well, only the first track recorded was used to characterize migratory behavior.

\section{Distributions and migratory behavior}

Utilization distributions (UDs) were calculated annually and for each bird from October through
March (Calenge 2006), using a grid size of $50 \mathrm{~km}$ and a bivariate normal kernel. We estimated the scale of first peak in variance of first-passage time (FPT, $176 \mathrm{~km})$ to determine a smoothing factor $(h=88 \mathrm{~km}$; Lascelles et al. 2016). Tracks were projected using a Lambert azimuthal equal-area projection. Areas were calculated for the $95 \%$ and $50 \%$ UDs to compare range and core areas of use, respectively. Because the number of individuals tracked can influence area of UDs, we iteratively calculated area (1000 iterations) at increasing sample sizes for each year (Hindell et al. 2003). To provide metrics of similarity and space use sharing, we calculated Bhattacharyya's affinity (BA) as a metric of overall similarity between UDs, where 0 indicates no overlap and 1 indicates complete overlap for the $100 \%$ UD, and 0.50 indicates complete overlap for the $50 \%$ UD (Fieberg \& Kochanny 2005).

To identify annual differences in the presence, duration, and timing of rapid long-distance migratory movements, we fitted non-linear models to the daily net-squared displacement (NSD) of each track (squared great-circle distance between each point and the breeding colony). Each track was fitted to a resident (logarithmic model), nomadic (linear model), disperser (single sigmoidal model), and 2 migratory models (double sigmoid), following Eq. (1):

$\mathrm{NSD}=\frac{\delta}{1+\exp \left(\frac{\theta-\mathrm{t}}{\varphi}\right)}+\frac{\delta^{*} \zeta}{1+\exp \left(\frac{\theta+2^{*} \varphi+2^{*} \varphi_{2}+\rho-\mathrm{t}}{\varphi_{2}}\right)}$

where the distance between summer and winter ranges $(\delta)$ was either held constant (migratory, $\zeta=1$ ) or allowed to vary (mixed migratory) (Bunnefeld et al. 2011, Spitz et al. 2017). The fit of each model type was assessed using Akaike's information criterion (AIC; Bunnefeld et al. 2011). In Eq. (1), $t$ is time along the track, $\theta$ is the midpoint of migratory movements, $\varphi$ quantifies the duration of the outbound migratory movement ( $\varphi_{2}$ indicates the inbound leg) and $\rho$ is the length of time spent on the winter range. We allowed flexible starting points along the first $60 \mathrm{~d}$ of each movement trajectory by first fitting models sequentially and minimizing AIC to find the best fit starting point (Spitz et al. 2017). We chose $60 \mathrm{~d}$, as this encompasses the autumn equinox period and the time frame prior to migration. We found this approach particularly helpful due to inherent error in geolocations and kittiwake behavior, as some individuals made short excursions or moved slowly away from the colony before making the rapid long-distance movements characterized with this method. The inclusion of the mixed migratory model allowed for different 
end points, corresponding to wider ranging, yet colony centric, distributions in the spring pre-laying period. Additionally, we tested for annual differences in the cumulative distance traveled and the maximum distance from the colony attained by each bird.

\section{Bathymetry and sea ice}

Bathymetry was extracted from ETOPO1 (Amante \& Eakins 2009) as the average depth within a $0.5 \times$ $0.5^{\circ}$ grid cell and then each point was categorized into bathometric habitats as follows: oceanic $(>3000 \mathrm{~m})$, slope $(>1000-3000 \mathrm{~m})$, shelf break $(>200-1000 \mathrm{~m})$, and continental shelf $(\leq 200 \mathrm{~m})$. Annual seasonal trends in bathymetric habitat use were assessed using generalized additive mixed models (GAMMs) with individual as a random effect and a quasi-Poisson log link function (Wood \& Scheipl 2014). Smoothers were included for each year, and then years were sequentially combined to identify the model with the lowest AIC. Models were assessed through residual plots and checked for overdispersion.

Sea ice concentrations were extracted from daily remote-sensed sea ice data from passive microwave sensors for each location from a $50 \times 50 \mathrm{~km}$ grid cell (Cavalieri et al. 1996). The minimum great circle distance to the sea ice edge (MASIE-NH, $4 \mathrm{~km}$ resolution; National Ice Center \& National Snow and Ice Data Center 2010) was extracted as a second metric of sea ice association. These 2 datasets were combined to identify locations where kittiwakes were associated with sea ice.

\section{Laboratory analyses}

\section{Stable isotopes}

Due to enrichment with each trophic transfer, stable isotope ratios of nitrogen provide an estimation of trophic level, while stable isotope ratios of carbon reflect geographic gradients in carbon sources (Hobson et al. 1994). Therefore, quantification of isotope space provides an integrated assessment of niche width along the axes of diet and habitat during the time feathers are grown. To quantify winter niche space, we sampled head feathers from prenuptial plumage. Feathers were washed in a 2:1 chloroform: methanol solution, cut into small pieces, and weighed to the nearest mg in tin capsules. Samples from 2011 were analyzed using a Carbo-Erba elemental analyzer interfaced with a Finnigan Delta Plus XP mass spectrometer (Light Stable Isotope Lab, UCSC). Feathers from 2014-2016 were analyzed at the University of Alaska Fairbanks Stable Isotope Facility using continuous-flow isotope ratio mass spectrometry (CF-IRMS) using a Delta+XP isotope ratio mass spectrometer (Thermo Electron) interfaced with an EA Costech ECS 4010. UCSC internal standards (pugel) were run at the University of Alaska Fairbanks Stable Isotope Facility and found to be comparable (Will et al. 2018, this Theme Section).

Stable isotope ratios are reported in delta notation as parts per thousand (\%) deviation from the international standards $\delta^{13} \mathrm{C}_{\text {PeeDee Belemnite }}$ and $\delta^{15} \mathrm{~N}_{\text {air }}$ as follows: $\delta X=\left[\left(R_{\text {sample }} / R_{\text {standard }}\right)-1\right] \times 1000$, where $X$ is ${ }^{13} \mathrm{C}$ or ${ }^{15} \mathrm{~N}$ and $R$ is the corresponding ratio ${ }^{13} \mathrm{C} /{ }^{12} \mathrm{C}$ or ${ }^{15} \mathrm{~N} /{ }^{14} \mathrm{~N}$. To compare core isotopic area occupied each year, we calculated standard ellipse areas (SEAs) within a Bayesian framework that is robust to small sample sizes and convex hulls to represent the total niche area occupied (Jackson et al. 2011).

\section{Corticosterone}

We measured corticosterone concentrations in head feathers (hereafter fCORT) to test for differences in stress levels accrued by birds during the prenuptial molt. In most cases, we analyzed 3 head feathers obtained from each bird $(\mathrm{n}=58)$; for 3 birds, only 2 head feathers were available, and a single head feather was available for 2 individuals. Each feather length was measured (to the nearest $0.5 \mathrm{~mm}, 25.5 \pm$ $3.5[\mathrm{SD}] \mathrm{mm})$, and all feathers in a sample were weighed collectively (to the nearest $0.1 \mathrm{mg}$, total sample mass: mean $=3.4 \pm 1.4 \mathrm{mg}$ ) to account for weight and size variability in feathers (Lattin et al. 2011, Will et al. 2014). Feather samples were cleaned in a 1 min wash in isopropanol (HPLC-grade, SigmaAldrich) (Will et al. 2018) and extracted in $5 \mathrm{ml}$ of HPLC-grade methanol (Fisher Scientific), which involved sonication for $60 \mathrm{~min}$ at $50^{\circ} \mathrm{C}$ followed by overnight incubation in a $50^{\circ} \mathrm{C}$ water bath (Bortolotti et al. 2008) and filtering via solid phase extraction with commercially available C18 columns. To control for loss of hormone during extraction, we added $2000 \mathrm{cpm}$ of $\mathrm{H}^{3}$-labeled corticosterone (NET399 Perkin Elmer), and adjusted final fCORT titers for $\%$ recovery of each individual sample (mean $\pm \mathrm{SD}$, $93.6 \pm 4.67 \%$ ). Feather extracts were air-dried, reconstituted in phosphate-buffered saline with gelatin, and analyzed using radioimmunoassay with a Sigma-Aldrich antibody (C 8784). All samples were analyzed in 2 assays, with intra- and inter-assay CV 
less than $2 \%$. For statistical analyses, fCORT titers were standardized by feather length $\left(\mathrm{pg} \mathrm{mm}^{-1}\right)$. We also found a significant relationship between fCORT titers and sample mass $\left(F_{1,59}=11.73, \mathrm{p}=0.001\right)$; therefore, in all statistical analyses we used fCORT

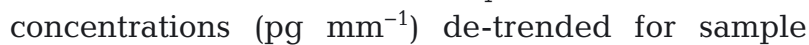
mass (Will et al. 2014).

\section{Statistical analyses}

To assess the influence of migratory behavior on fCORT, we used linear models with fCORT as the response and departure or return date from the colony as predictors. To test for spatial structure in birds relative to fCORT concentration in head feathers, we scored all individual samples based on a deviation of fCORT concentrations relative to average fCORT (1.64 $\mathrm{pg} \mathrm{mm}^{-1}$ ). We excluded birds with intermediate levels of fCORT (within $3 \%$ of the mean, $16 \%$ of birds) from the subsequent analysis grouping birds by low and high fCORT. We then calculated the BA between the $50 \%$ UD for high fCORT and low fCORT birds across the migration period (1 November to $1 \mathrm{March}$ ), for an interval of
$25 \mathrm{~d}$ (approximately the amount of time it takes a feather to grow at 1-2 $\mathrm{mm} \mathrm{d}^{-1}$, A.S. Kitaysky unpublished) to determine potential temporal windows of spatial separation. Next, we randomized the group identity of these individuals across potential windows of spatial separation, for intervals of 14$30 \mathrm{~d}$ to identify BA significantly different than random (Breed et al. 2006).

All analyses and data processing were done in $\mathrm{R}$ (3.3.1, R Core Development Team 2016), significance was considered to be $\mathrm{p}<0.05$, and Bonferroni adjusted p-values were used in pairwise comparisons. Means are given \pm SD to emphasize variation within groups.

\section{RESULTS}

\section{Distributions}

From October through March, red-legged kittiwakes used areas in the northern Bering Sea, western Bering Sea, Kuril Islands, and western subarctic gyre with core areas on the shelf in the northwestern Bering Sea and near the Kamchatka Strait in the

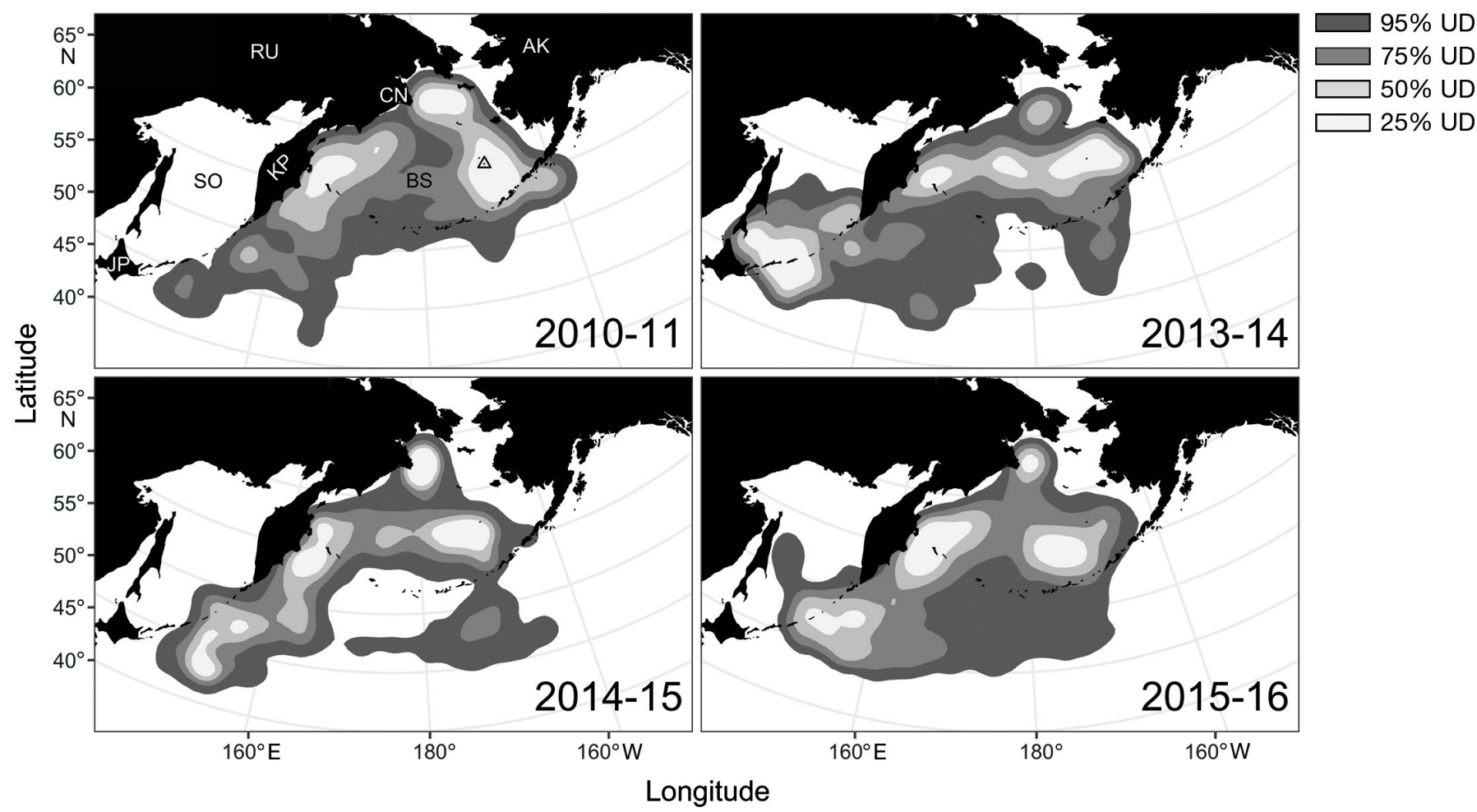

Fig. 1. Annual at-sea utilization distributions (UDs) of red-legged kittiwakes from October through March. St. George Island is indicated by a triangle, and place names are as follows: Alaska (AK), Russia (RU), Japan (JP), Sea of Okhotsk (SO), Kamchatka Peninsula (KP), Cape Navarin (CN), and Bering Sea (BS). Smoothing factor $h=88 \mathrm{~km}$ 


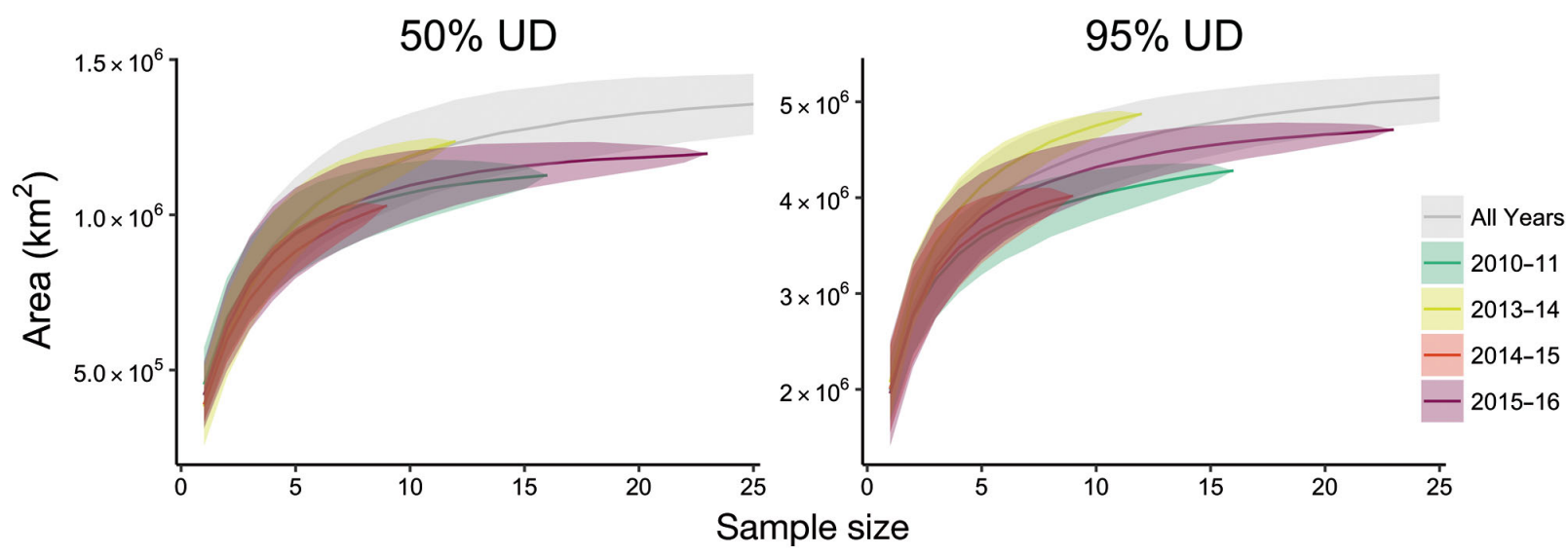

Fig. 2. Cumulative area of the $50 \%$ and $95 \%$ utilization distributions (UDs) for increasing sample sizes of red-legged kittiwakes. The shaded area is the standard deviation for each sample size from 1000 iterations

vicinity of the Commander Islands (Fig. 1). Across all years, $39 \%$ of birds visited the northern Bering Sea shelf near Cape Navarin, Russia, and this did not differ significantly among years (multiple comparison chi-squared test, $\mathrm{p}>0.05)$. In the 3 latter winters, birds visited the Sea of Okhotsk (47\%), and the percentage of birds visiting this region was the greatest in 2013-2014 (67\%). The randomized cumulative area curve of individuals tracked in all years appears to reach an asymptote even with the relatively small number of individuals tracked each year (Fig. 2). This indicates that our sample sizes are large enough to capture common high-use areas. The area of individ- ual core and range UDs did not differ among years (Table 2).

Among years, BA indicated little overlap in core areas $(0.240 \pm 0.044)$ and relatively similar ranges $(0.755 \pm 0.035)$. Among individuals in the same year, the BA between the $95 \%$ UDs was significantly higher in 2010-2011 $(0.412 \pm 0.16$, post hoc $\mathrm{p}=0.003)$ than all other years (pooled: $0.360 \pm 0.009$ ), indicating medium similarity of individual ranges; however, there was more homogeneity in ranges among birds in 2010-2011 (Table 2). The BA of individual core areas did not differ among years and indicates low similarity (Table 2).

Table 2. Yearly comparison of distribution, migration, and physiological parameters from red-legged kittiwakes deployed and retrieved with geolocation loggers from St. George Island, Alaska, USA. Stable isotope values and corticosterone concentrations (fCORT) are from head feathers grown in late winter (February to March), and sample sizes for these measurements are given in parentheses. Yearly samples sizes from geolocation-derived parameters are $\mathrm{n}_{2010-11}=15, \mathrm{n}_{2013-14}=12, \mathrm{n}_{2014-15}=9, \mathrm{n}_{2015-16}=23$. BA: Bhattacharyya's affinity, UD: utilization distribution. Means are given \pm SD; significant values $(p<0.05)$ are shown in bold

\begin{tabular}{|c|c|c|c|c|c|c|}
\hline & $2010-2011$ & $2013-2014$ & $2014-2015$ & $2015-2016$ & $F$ & $\mathrm{p}$ \\
\hline Area of individual $50 \%\left(\mathrm{~km}^{2}\right)$ & $456000 \pm 131087$ & $383750 \pm 127540$ & $393056 \pm 60799$ & $420326 \pm 107013$ & 1.113 & 0.296 \\
\hline Area of individual $95 \%\left(\mathrm{~km}^{2}\right)$ & $2036167 \pm 355951$ & $2090833 \pm 394736$ & $2018611 \pm 490550$ & $1976522 \pm 562618$ & 0.148 & 0.702 \\
\hline BA among individual $50 \%$ UD & $0.090 \pm 0.008$ & $0.050 \pm 0.009$ & $0.081 \pm 0.013$ & $0.076 \pm 0.005$ & 2.758 & 0.096 \\
\hline BA among individual $95 \%$ UD & $0.412 \pm 0.016$ & $0.321 \pm 0.02$ & $0.378 \pm 0.027$ & $0.368 \pm 0.011$ & 4.143 & 0.042 \\
\hline Outbound migration timing $(\mathrm{d})$ & Nov $29 \pm 37$ & Nov $10 \pm 30$ & Nov $24 \pm 18$ & Nov $7 \pm 28$ & 8.053 & 0.006 \\
\hline Arrival on wintering grounds & Jan $20 \pm 21$ & Dec $31 \pm 33$ & Jan $6 \pm 26$ & Jan $9 \pm 35$ & 1.265 & 0.265 \\
\hline Departure from wintering grounds & Feb $17 \pm 18$ & Feb $3 \pm 25$ & Feb $14 \pm 17$ & Feb $18 \pm 16$ & 1.637 & 0.206 \\
\hline Return to colony region & Mar $5 \pm 16$ & Mar $1 \pm 27$ & Mar $7 \pm 36$ & Mar $15 \pm 16$ & 1.637 & 0.206 \\
\hline Duration $(d)$ on wintering grounds $(\rho)$ & $30.9 \pm 32$ & $38 \pm 35.8$ & $42 \pm 29.7$ & $43.7 \pm 31.6$ & 1.573 & 0.215 \\
\hline Outbound migration duration $(\varphi)$ & $11.8 \pm 6.4$ & $11.5 \pm 5.4$ & $9.8 \pm 7.4$ & $14.5 \pm 7.7$ & 0.807 & 0.373 \\
\hline Return migration duration $(\varphi)$ & $3.6 \pm 3.7$ & $5.8 \pm 5.3$ & $4.7 \pm 6.5$ & $5.6 \pm 4.7$ & 1.384 & 0.244 \\
\hline Maximum distance from colony (km) & $2337 \pm 486$ & $2858 \pm 624$ & $2688 \pm 416$ & $2451 \pm 517$ & 0.567 & 0.455 \\
\hline Day at maximum location & Feb $5 \pm 16$ & Jan $15 \pm 32$ & Jan $22 \pm 27$ & Jan $23 \pm 32$ & 2.017 & 0.161 \\
\hline Cumulative distance traveled $(\mathrm{km})$ & $27287 \pm 3413$ & $26558 \pm 1771$ & $25210 \pm 1637$ & $26630 \pm 2680$ & 1.074 & 0.304 \\
\hline$\delta^{15} \mathrm{~N}(\%)$ & $16.00 \pm 0.48(17)$ & $15.45 \pm 0.54(7)$ & $15.23 \pm 0.42(9)$ & $15.53 \pm 0.40(23)$ & 13.69 & $<0.001$ \\
\hline$\delta^{13} \mathrm{C}(\%$ o $)$ & $-18.30 \pm 0.18(17)$ & $-18.29 \pm 0.27(7)$ & $-18.50 \pm 0.22(9)$ & $-18.55 \pm 0.20(23)$ & 14.86 & $<0.001$ \\
\hline fCORT $\left(p g \mathrm{~mm}^{-1}\right)$ & $1.61 \pm 0.263(17)$ & $1.731 \pm 0.190(7)$ & $1.686 \pm 0.414$ & $1.665 \pm 0.402(28)$ & 0.107 & 0.745 \\
\hline
\end{tabular}




\section{Migration movements}

All red-legged kittiwake tracks fit to a migratory model based on net-squared displacement from the colony (migratory $n=9$, mixed migratory $n=50$ ). The initiation of the outbound migration $10 \%$ of migratory movement) occurred in October through December, and was significantly different among years (Table 2), as outbound migration occurred later in 2015-2016 than in 2010-2011 (post hoc p = 0.026). The timing of arrival on the wintering grounds was not significantly different among years, nor was departure from the wintering grounds, the duration of time spent in the wintering areas, time when birds returned to the colony, or the duration of each migratory leg (Table 2). However, the outbound migration was significantly longer than the inbound migration

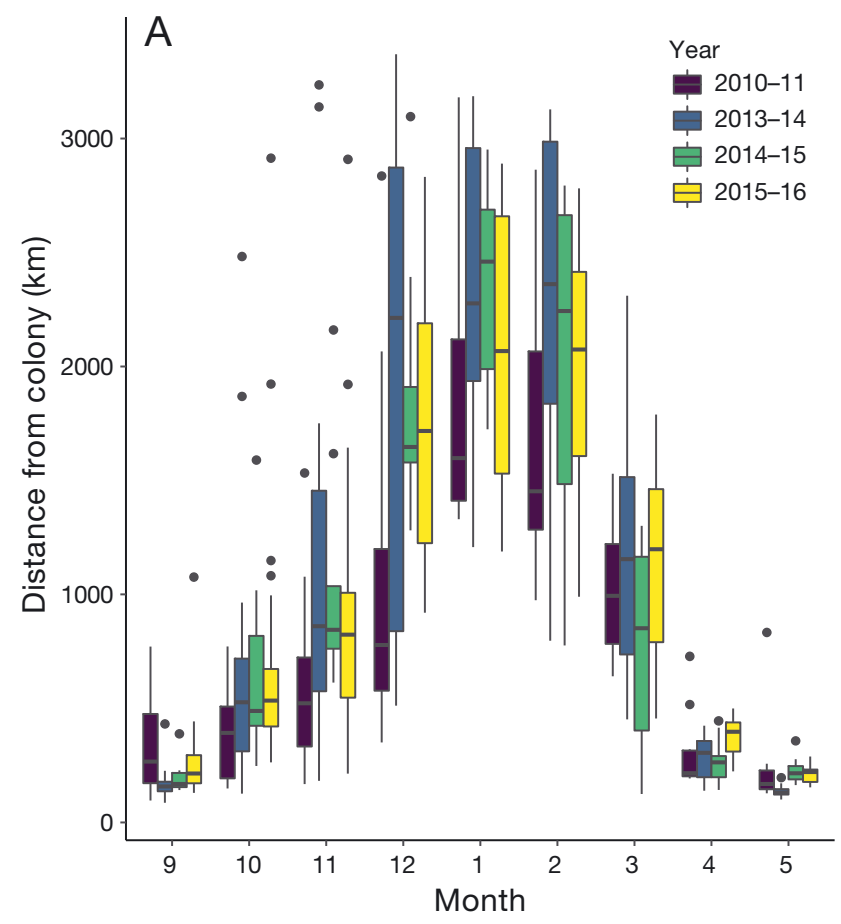

Fig. 3. Seasonal movements of wintering red-legged kittiwakes with (A) Mean monthly maximum distance from St. George Island, Alaska, USA, and (B) $50 \%$ utilization distribution (UD) for autumn (September, October, and November), winter (December, January, and February), and spring (March, April, and May), with 2010-2011 in purple, 20132014 in blue, 2014-2015 in green, and 2015-2016 in yellow. In $\mathrm{A}$, the boxes denote the 0.25 and 0.75 quartiles, the median is the line in each box, and the whiskers are $1.5 \times$ the interquartile range. St. George Island is indicated by a triangle (paired $t$-test, $\mathrm{p}<0.001$ ). In general, these migratory patterns resulted in relatively constrained autumn (September to November) and spring (March to May) distributions in the eastern Bering Sea, with a short wintering period in the western Bering Sea and subarctic (Fig. 3). Overall, the maximum distance from the colony was not significantly different among years, nor was the time when birds arrived there, or the cumulative distance traveled from October through March (Table 2).

\section{Habitat use}

Red-legged kittiwakes predominantly used oceanic habitats $(51 \pm 14 \%)$, although the use of these habitats was typically highest from January to March (Fig. 4).

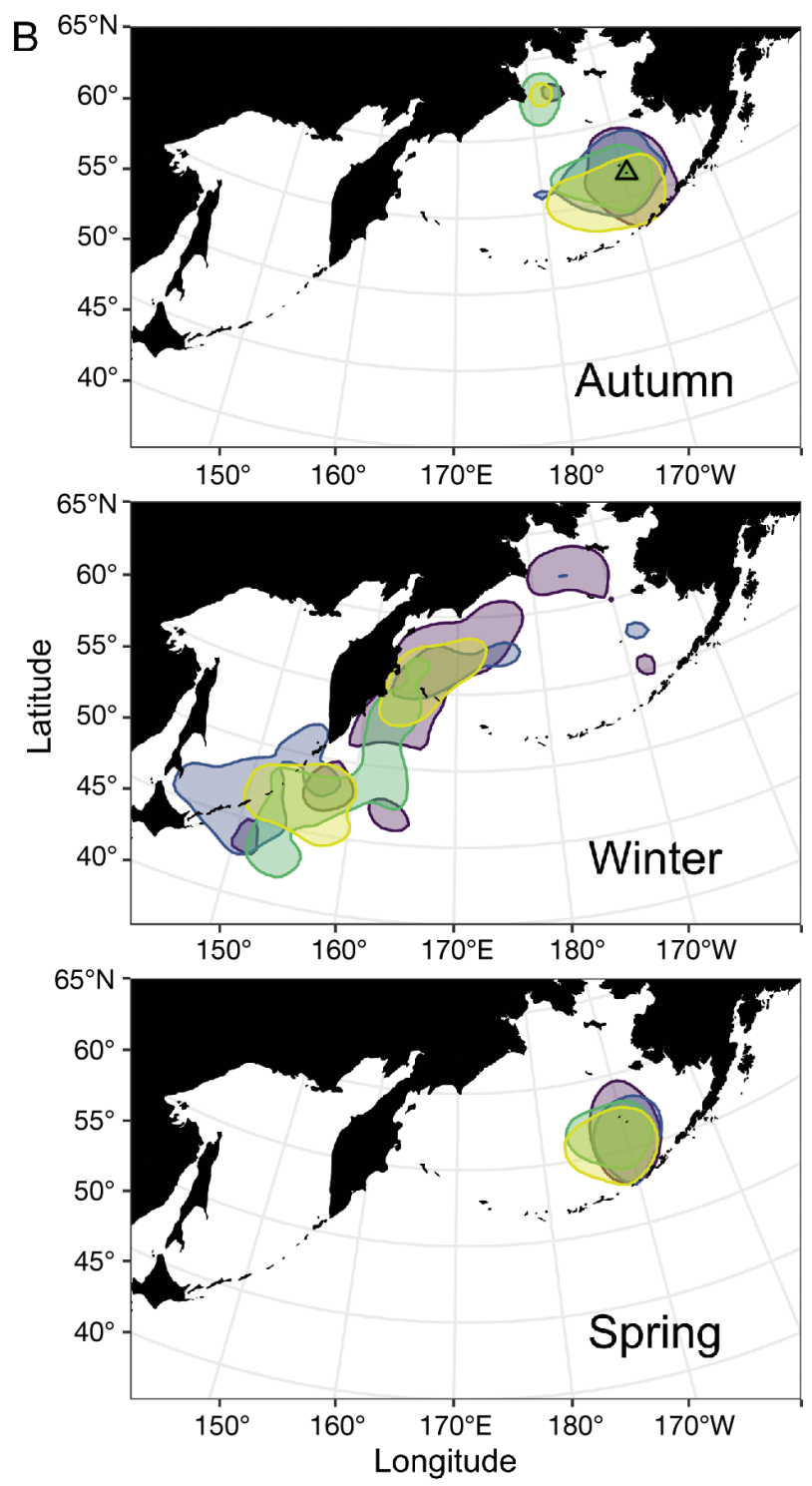


Annually, the seasonal use of oceanic habitats was relatively similar between the later 3 years, while the inclusion of a separate smoother for 2010-2011 improved AIC scores (Table S1 in the Supplement at www.intres.com/articles/suppl/m593p231_supp.pdf). Seasonally, the overall pattern of shelf use was similar (Fig. 4), and the lowest AIC score resulted from a 2-group model with 2010-2011 and 2013-2014 combined. Shelf use was highest in 2010-2011 (2010-2011: $36 \pm 8 \%)$ and lowest in 2015-2016 (16 $\pm 8 \%$ ). The annual percentage of time birds spent using the shelf break was minimal and did not differ by year (ANOVA: $5.2 \pm 3.0 \%, F_{1,57}=$ $0.002, \mathrm{p}=0.968$ ); the lowest AIC score resulted from the model with all years combined. Seasonal use of the slope had a unique pattern in 2013-2014, and AIC values were reduced with 1 smoother for 2013-2014, and a second smoother for the other years, but overall use of the slope did not differ by year (ANOVA: $17.9 \pm 6.4 \%$, $F_{1,57}=1.16, \mathrm{p}=0.286$, Fig. 4).

From November to May, red-legged kittiwakes spent on average $8.7 \%$ of each month overlapping with, or within $100 \mathrm{~km}$, of the sea ice, and 2010-2011 had significantly more sea ice interactions than the other 3 years (LMM: $F_{3,59}=7.04, \mathrm{p}<0.001$ ). There was no significant difference in sea ice interactions between the other 3 years (LMM: $F_{2,44}=0.44, \mathrm{p}=$ 0.6467, Fig. 5). Both the cumulative maximum extent of sea ice and the location of kittiwake-ice interactions shifted annually, occurring across the Bering Sea shelf, along the coast of Kamchatka, the Kuril Islands, and in the Sea of Okhotsk (Fig. 5).

\section{Period of pre-nuptial molt}

The $\delta^{15} \mathrm{~N}$ values from red-legged kittiwake feathers ranged from a minimum of $14.37 \%$ to a maximum of $17.05 \%$, and within this range there were differences among years, with $\delta^{15} \mathrm{~N}$ significantly higher in 2011 than in all other years (post hoc $\mathrm{p}=0.006$, Fig. 5), likely indicating a higher trophic level diet during this year. $\delta^{13} \mathrm{C}$ values $(\mathrm{min} .=-19.01$, $\max .=$ -17.97 ) were significantly different between all year combinations except 2011 and 2014 ( $p=0.903$ ) and 2015 and 2016 ( $p=0.691$; Table 2). As determined by maximum likelihood estimates of the SEA, the size of the 2-dimensional isotopic niche space did not significantly differ among the 4 winters (Fig. 6).

Concentrations of corticosterone in feathers were not significantly different among study years (Table 2). Likewise, within-year variance was not different among years $(p>0.05)$. We did not find a significant linear relationship between migratory parameters

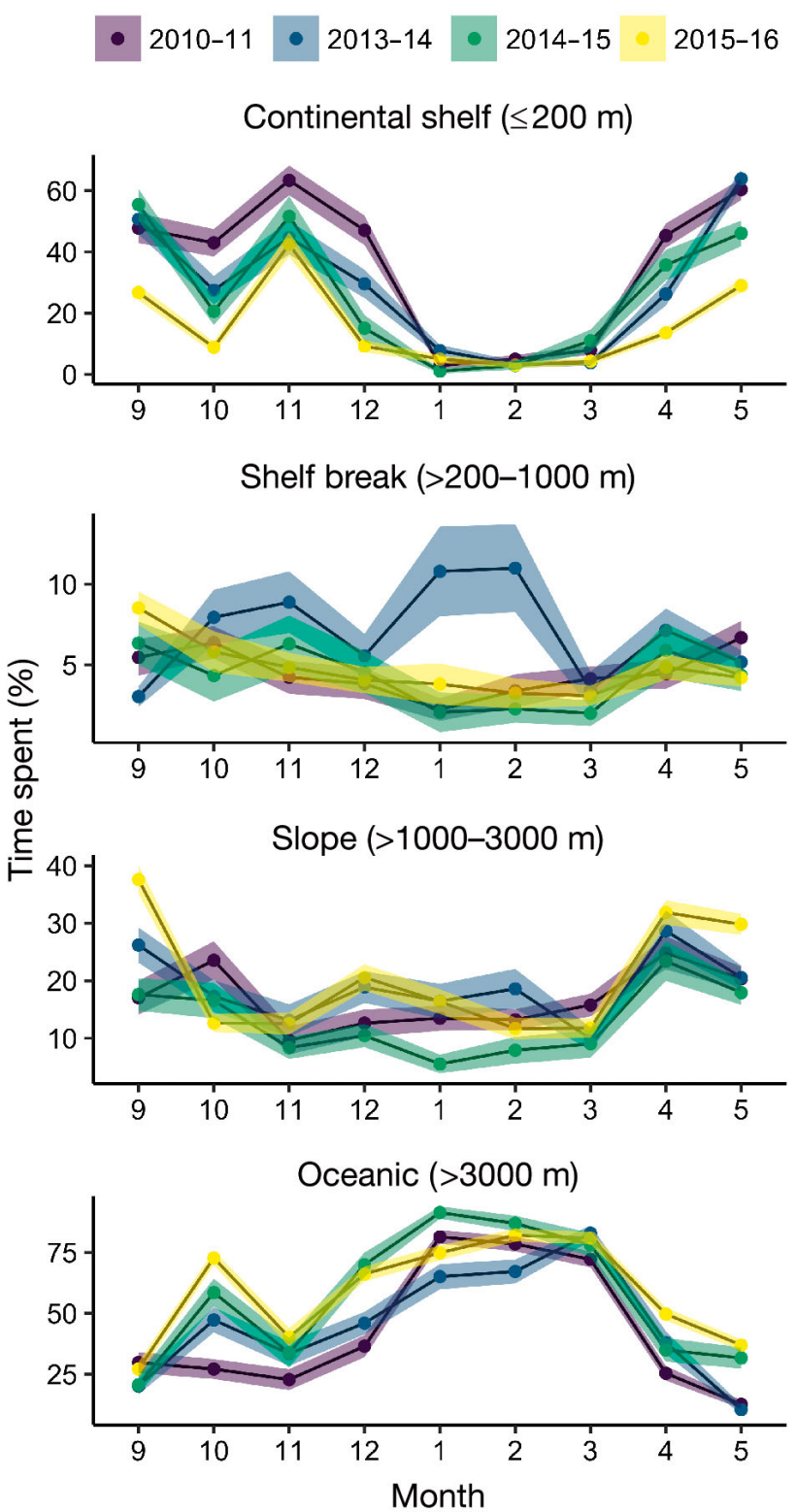

Fig. 4. Monthly percentage of time spent in bathymetric habitats of the North Pacific by wintering red-legged kittiwakes. The shaded area is the standard error for each month

and fCORT ( $p$ > 0.05). Average fCORT was $1.64 \mathrm{pg}$ $\mathrm{mm}^{-1} ; 14$ birds comprised the high fCORT group $(18.9 \pm 10.5 \%$ above the mean), 22 birds were in the low fCORT group $(-13.1 \pm 6.5 \%$ below the mean), while 7 birds had average concentrations of fCORT (within $3 \%$ of the mean) and were excluded from subsequent analysis looking at spatial separation. Across the migratory period, the only timeframe with spatial separation between birds with high and low fCORT occurred in February, corresponding to the estimated period of feather growth (Gabrielson \& Lincoln 1959). Birds with high and low fCORT values 


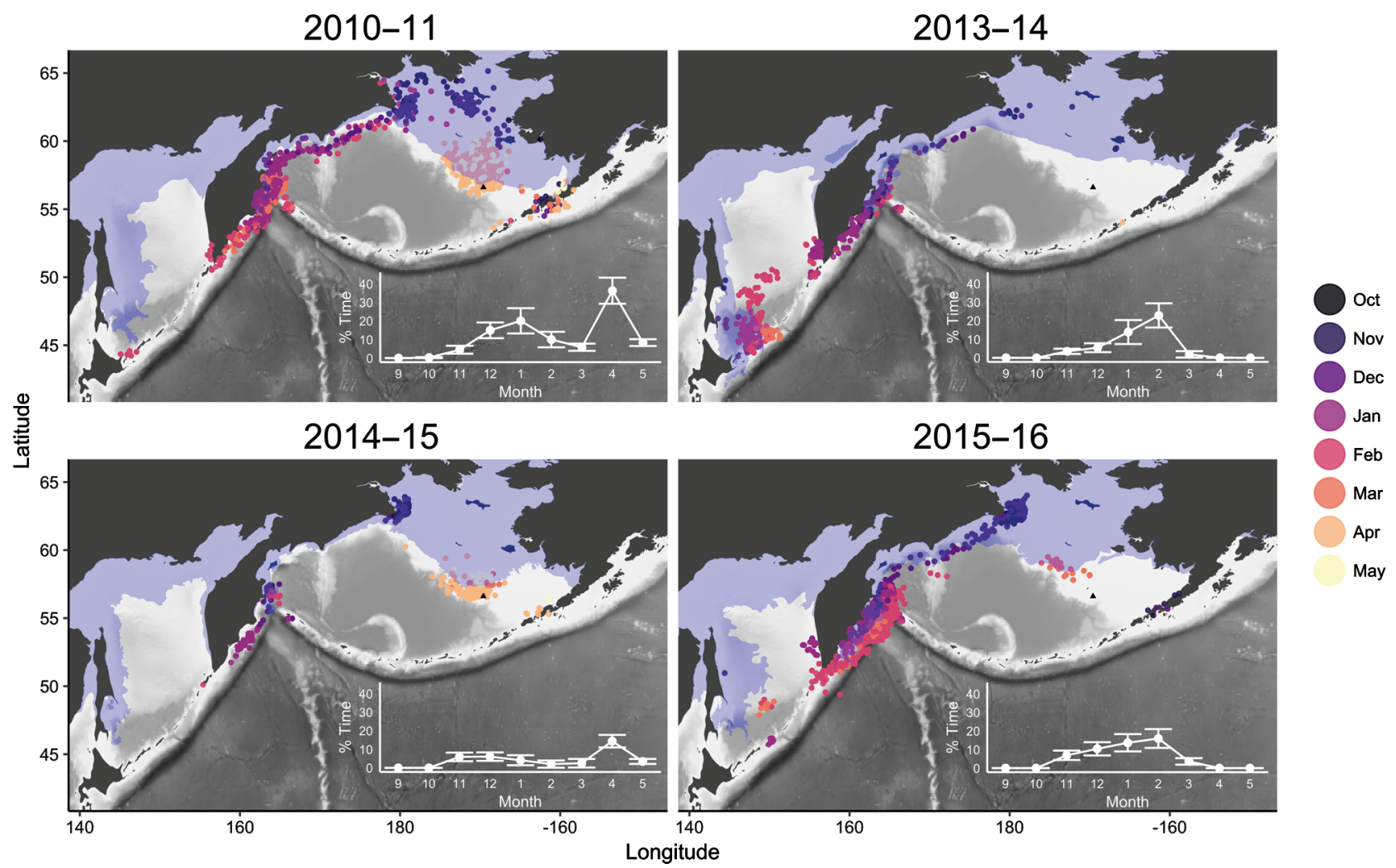

Fig. 5. Association of red-legged kittiwakes with sea ice. Twice daily locations of red-legged kittiwakes within $100 \mathrm{~km}$ of the sea ice edge (and within the sea ice) overlaid on the cumulative maximum sea ice extent for each year (in lavender). Locations are colored by month. Inset into each map is the percentage of time each month birds were associated with sea ice. Error bars indicate \pm SD. St. George Island is indicated by a small black triangle

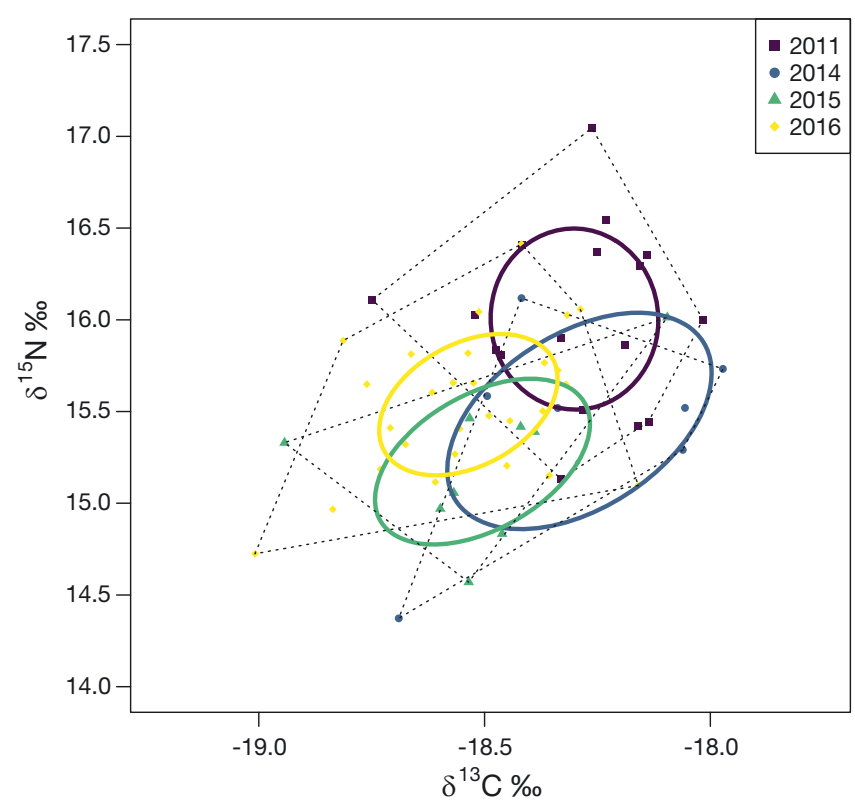

Fig. 6. Annual stable isotope values from nape feathers of red-legged kittiwakes $(\mathrm{n}=61)$, overlaid with convex hulls (dashed lines) and small sample-size corrected $40 \%$ standard ellipses (SEAc) had significantly spatially separated $50 \%$ UD, determined via BA, from early February to early March (Fig. 7). Reinforcing this spatial separation, carbon stable isotope values were also significantly different between birds of high and low fCORT $\left(\delta^{13} \mathrm{C}\right.$, High fCORT $=-18.35 \pm 0.25 \%$, Low fCORT $=-18.45 \pm$ $\left.0.19 \%, F_{1,34}=18.09, \mathrm{p}<0.001\right)$. Moreover, birds with higher fCORT were foraging at a significantly lower tropic level than their counterparts with lower fCORT $\left(\delta^{15} \mathrm{~N}\right.$, High fCORT $=15.49 \pm 0.43 \%$, Low fCORT $=$ $15.84 \pm 0.53 \%, F_{1,34}=10.87, \mathrm{p}=0.002$ ).

\section{DISCUSSION}

Across $4 \mathrm{yr}$, red-legged kittiwakes consistently returned to the same general regions of the Bering Sea and western North Pacific during their winter migrations. Within this region, core areas changed annually, and individuals varied in where and when they moved between bathymetric habitats, especially in the autumn. Since long-distance migratory movements were initiated roughly 2 mo after the breeding 

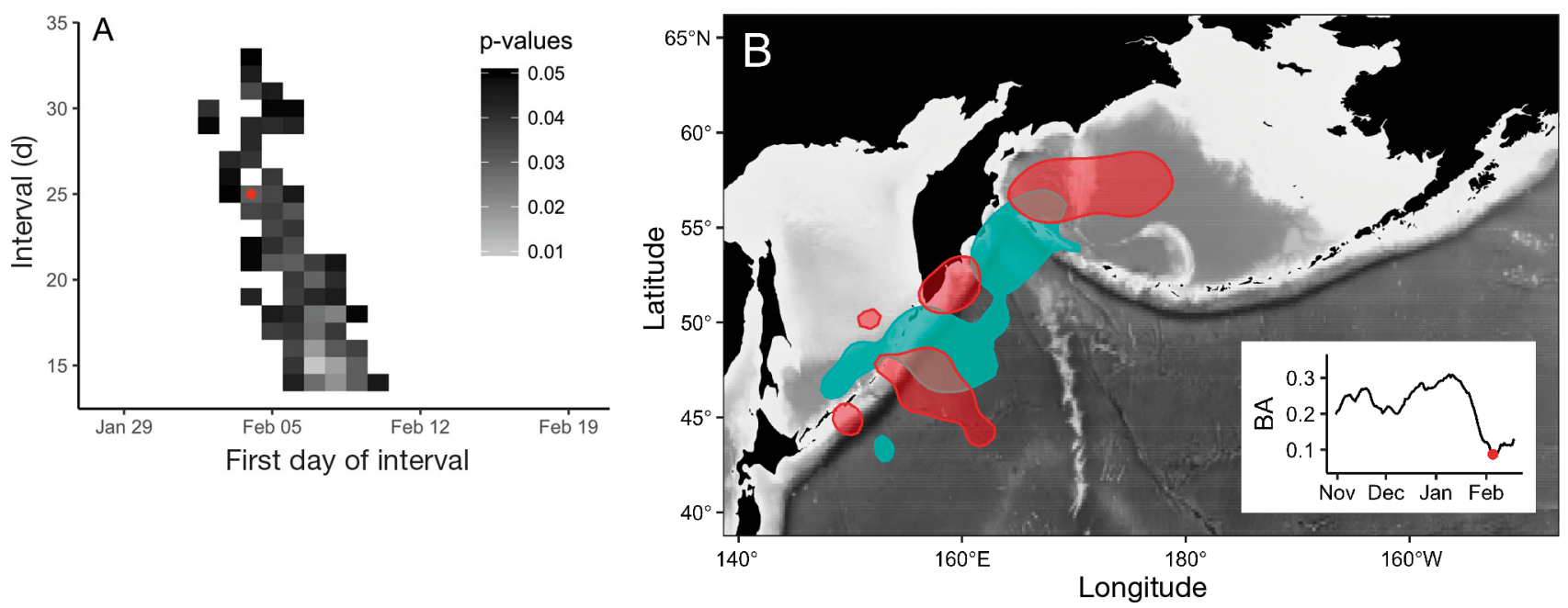

Fig. 7. Spatial separation between red-legged kittiwakes with above and below average corticosterone concentrations in head feathers grown at the end of the wintering period (fCORT). (A) Significant p-values for intervals beginning on 30 January to 18 February, with intervals from 14-35 d. The red dot corresponds to the day and interval shown in panel B. (B) Representative kernel density plot ( $50 \%$ utilization distribution, UD) from the significant time period, with birds with high fCORT levels in red and low fCORT levels in turquoise (Bhattacharyya's affinity $[\mathrm{BA}]=0.0873, \mathrm{p}=0.03$ ). Inset: BA between the 2 groups for the $50 \%$ UD from 1 October to 18 February for a sliding interval of $25 \mathrm{~d}$. The representative interval is highlighted with a red dot

season ended, the timing likely relates to local environmental conditions rather than life-history drivers. Kittiwakes used multiple oceanographic habitats, but the majority of their time was spent in deep pelagic waters, followed by time spent foraging over shallow shelf waters of the eastern Bering Sea. Annually, the relatively cooler year of 2010-2011 was unique, as birds stayed on the southeastern Bering Sea shelf longer, had higher $\delta^{15} \mathrm{~N}$, and slightly higher homogeneity among individual wintering areas. Birds were more likely to visit the Sea of Okhotsk in 2013-2014, whereas distributions were the most pelagic in 2015-2016. Associated with these differences in migration behavior, we found no significant annual difference in feather corticosterone. Nonetheless, we found a significant spatial separation between birds with relatively high and low fCORT across all years, indicating specific regions where and when individual red-legged kittiwakes consistently experienced lower prey availability (as reflected in elevated fCORT). Our evidence of a 'stress landscape' suggests that regions in the Bering Sea basin consistently had lower prey availability, at least in February, suggesting why it may be beneficial for red-legged kittiwakes to migrate out of the Bering Sea.

Red-legged kittiwakes wintered in the western Bering Sea and western subarctic regions. Yet, birds could have headed east, as 1 bird did in November of 2015, taking a short trip to the Gulf of Alaska.
This is not unprecedented, as a flock of juvenile red-legged kittiwakes was observed once in southeast Alaska (Siegel-Causey \& Meehan 1981), suggesting that the tendency to head west may be learned, or may be a phenomenon of our study years. Preference for western regions of the North Pacific is also exhibited by the widely ranging wintering black-legged kittiwakes that breed on the Pribilof Islands (Orben et al. 2015b), and has been observed during at-sea surveys of marine mammals and birds (Shuntov 1974, Springer et al. 1999). The western subarctic regions have higher primary productivity, along with a higher diversity of mesopelagic fishes than the eastern subarctic (Beamish et al. 1999, Springer et al. 1999). The most abundant myctophid species in the North Pacific, Stenobrachius leucopsarus, is thought to spawn sometime from December through March (Smoker \& Pearcy 1970). This is also the species recorded in summer diets of red-legged kittiwakes (Sinclair et al. 2008). If spawning behaviors make myctophids vulnerable to predation, this would provide consistent winter foraging opportunities for kittiwakes. Myctophids are thought to be vulnerable to being trapped at the surface by currents (Flynn \& Williams 2012). The western subarctic has more eddies than the eastern portion (Bograd et al. 1997), and wintering redlegged kittiwakes appear to be concentrated in areas of strong currents: Cape Navarin, Kamchatka Strait, and along the Kuril Islands. 
Ocean fronts and eddies concentrate prey for marine predators, and are especially important for surface-feeding seabirds (Bost et al. 2009, Scales et al. 2014). For instance, instead of foraging over slope regions, chick-rearing black-legged kittiwakes forage in more distant deep waters, targeting eddies (Paredes et al. 2014). Starting in the northern Bering Sea, red-legged kittiwakes consistently occupied the region to the southwest of Cape Navarin where along-shelf currents and the western Bering Sea Current converge to flow up over the shelf (Stabeno et al. 1999). Further investigation is needed to understand what mechanisms make this region profitable for kittiwakes and other marine predators in the autumn. The regions between Cape Navarin and the Karaginsky Gulf were not often frequented by wintering kittiwakes, while the associated basin areas appear to be associated with higher levels of stress incurred by birds in late February. In the western Bering Sea, fronts are often closer to each other than in the east due to the narrow continental shelf (Belkin 2016), perhaps limiting foraging opportunities. Instead, core areas associated with lower stress levels were located over the deep waters of Kamchatka Pass and Near Straight, where surface currents move out of the Bering Sea at up to $100 \mathrm{~cm} \mathrm{~s}^{-1}$, some of the fastest current speeds in the Bering Sea (Stabeno et al. 1999, 2005). This region was a consistent hotspot, and due to its proximity to colonies in the western Aleutians and Commander Islands, there is the potential for high overlap between birds from multiple colonies. Red-legged kittiwakes did not appear to frequent the other Aleutian passes, even though 3 of their 4 breeding colonies are within or proximate to this island chain. The passes through the Kuril Islands were not consistently used by wintering redlegged kittiwakes, nor was the southern Sea of Okhotsk where the East Sakhalin Current moves towards the Kuril Island chain (Andreev \& Shevchenko 2008). This selective use of areas might be due to kittiwake reliance on both ample prey resources and the need for physical processes, such as currents, to then make prey available at the surface.

Red-legged kittiwakes encountered sea ice across their range and throughout the non-breeding period. Due to the spatial resolution of our geolocation data, we cannot shed light on the direct nature of how, or if, red-legged kittiwakes use the marginal ice zone. Certainly, compared to a pagophilic species like Mandt's black guillemot Cepphus grylle mandtii, their use of sea ice is minimal (Divoky et al. 2016). Considering the seemingly low level of spatial association with sea ice, it is somewhat surprising that red-legged kittiwake reproductive timing and productivity, and wintering condition (fCORT, isotopic niche) appeared to be related to sea ice dynamics (Byrd et al. 2008b, Zador et al. 2013, Will et al. 2018). However, there is a spatial association between redlegged kittiwakes and regions of seasonal sea ice, predominantly in the late autumn and winter, that could perhaps help to explain possible links between sea ice, and breeding parameters and foraging ecology of red-legged kittiwakes. For instance, the higher association of red-legged kittiwakes with sea ice in 2010-2011 may be an artifact of higher abundances of prey species on the shelf, such as amphipods, due to consecutive cold years of higher ice abundance and the associated shift in trophic dynamics (Pinchuk et al. 2013). In all years, red-legged kittiwakes returned to the eastern Bering Sea in March, emphasizing the importance of prey resources in this region for kittiwake pre-laying condition (e.g. Shultz et al. 2009, Renner et al. 2014), and potentially dampening the influence of migration quality on subsequent reproductive success.

We found no significant differences in fCORT levels among our study years, although in some cases our annual sample sizes were fairly small. In context, the birds we tracked had some of the lowest fCORT values seen in the last century (Will et al. 2018). Although we found annual and individual variability, at the broad scale we found distributions, migrations, and stable isotopes to be relatively consistent among winters. This could explain why fCORT values were similar as well. Yet, we found significant spatial separation in birds with high and low fCORT across all years. Surprisingly, birds continued using the deep oceanic waters of the Bering Sea basin despite experiencing apparent food limitation here and consuming a lower trophic level diet. This may be indicative of individual allostatic loads (e.g. Schultner et al. 2013 and references therein), consistency in wintering movements, and/or that availability of prey in deep water ocean areas might be high under certain environmental conditions, but our relatively short time series of observations failed to detect such variability. This is also a period of the annual cycle when red-legged kittiwakes spend the majority of their time sitting on the water (Orben et al. 2015a), and this sedentary tendency might accentuate the observed stress landscape. A persistent use of the same wintering ground regardless of local feeding conditions might make red-legged kittiwakes vulnerable to climate-associated changes in those areas.

Are red-legged kittiwakes employing a specialist strategy during the winter? Compared to black- 
legged kittiwakes, they do appear to be more specialized during the winter, as red-legged kittiwakes consistently occupied a smaller, somewhat restricted wintering area and isotopic niche space (Orben et al. $2015 a, b)$. However, there is still much more to understand about the exact nature of their wintering foraging ecology, individual consistency, and seasonal shifts in diets. Red-legged kittiwakes should certainly not be considered extreme migratory specialists, as they showed the capacity to annually adjust timing of outbound migrations, and high diversity between individual core use areas within their wintering range. Yet, across our 4 study years, they employed a relatively consistent wintering strategy, along with an apparent willingness to incur higher stress levels in specific regions. If red-legged kittiwakes are targeting spawning myctophids or squids across their wintering range, this would provide further evidence of foraging specialization, that in most years is likely highly profitable. There is some evidence that through the 1990s, the abundances of myctophids in the subarctic North Pacific increased (Beamish et al. 1999), potentially corresponding to upward population trends in red-legged kittiwakes and the stability of the ecosystem's apparent carrying capacity for this marine predator (Goyert et al. 2017).

\section{IMPLICATIONS}

Our 4 years of tracking highlight the persistence in wintering areas and behaviors in a surface foraging seabird species that is capable of traversing the entire North Pacific, like its congener the black-legged kittiwake (Orben et al. 2015b). Therefore, potential threats and risks to this population should be considered within the context of this putatively specialized spatial behavior, especially given that climate change is expected to continue to have large-scale impacts on marine ecosystems over the next decades (Henson et al. 2017). Though not considered at risk for direct or indirect fishery interactions, the winter range of red-legged kittiwakes does overlap in space and time with fisheries in the western Bering Sea and Kuril regions, and further investigation is warranted, as cumulative impacts can act in synergy (Maxwell et al. 2013). Our evidence for a consistent 'stress landscape' pattern could compound these impacts. We were able to track birds during 4 winters, but it is important to note that red-legged kittiwakes can live upwards of $25 \mathrm{yr}$ (The North American Bird Banding Laboratory, Patuxent Wildlife Research Center), so for an individual bird, $4 \mathrm{yr}$ represents only $\sim 17 \%$ of its adult life. As the next step, and given that other seabirds show both individual fidelity and flexibility in migratory behavior, it would be informative to track individual birds during multiple winters to understand the degree of flexibility individuals may have. This is particularly pertinent, as a chick hatched in 2017 could live until 2040+, facing life in a rapidly changing ecosystem altered by multiple climatedriven stressors (Henson et al. 2017). In light of past declines in red-legged kittiwake populations, we can expect similar population volatility as marine communities restructure in the arctic and subarctic North Pacific, as this seabird has a consistent reliance on both ecosystems.

Acknowledgements. This research was funded in part by the North Pacific Research Board projects B63, 911, and 1409, JSPS Kakenhi grant 16H02705, and by the Green Network of Excellence Program Arctic Climate Change Research Project of the Ministry of Education, Culture, Sports, Science and Technology in Japan. Bird captures and handling were approved by the Animal Care and Use Committee of the University of California Santa Cruz and the University of Alaska Fairbanks and by permits from the USFWS and the State of Alaska. We are highly indebted to 6 years of field teams including S. Dean Kildaw, John Harley, Caitlin Kroeger, Vijay Patil, Don Lyons, Rolanda Steenweg, Nobuhiko Sato, and Dale Kikuchi, and assistance with logistics from the St. George Traditional Council, David Irons, Robb Kaler, Marc Romano, Karin Holser, and Pricilla Wohl (NORTAC). We sincerely thank the Alaska Maritime National Wildlife Refuge for their long-term efforts to monitor seabird populations on St. George Island. We thank Rebecca Young, George Hunt Jr., and 3 anonymous reviewers who provided constructive comments on earlier drafts. This is NPRB contribution number 663.

\section{LITERATURE CITED}

Amante C, Eakins BW (2009) ETOPO1 1 Arc-Minute Global Relief Model: procedures, data sources and analysis. Tech Memo NESDIS NGDC-24. NOAA National Geophysical Data Center, Boulder, CO

Andreev AG, Shevchenko GV (2008) Interannual variability of water transport by the East Kamchatka and East Sakhalin Currents and their influence on dissolved oxygen concentration in the Sea of Okhotsk and subarctic Pacific. Russ Meteorol Hydrol 33:657-664

Beamish RJ, Leask KD, Ivanov OA, Balanov AA, Orlov AM, Sinclair B (1999) The ecology, distribution, and abundance of midwater fishes of the Subarctic Pacific gyres. Prog Oceanogr 43:399-442

Belkin IM (2016) Comparative assessment of the West Bering Sea and East Bering Sea Large Marine Ecosystems. Environ Dev 17:145-156

BirdLife International (2017) Rissa brevirostris. The IUCN Red List of Threatened Species 2017: e.T22694502A 118920892. http://dx.doi.org/10.2305/IUCN.UK.2017-3. RLTS.T22694502A118920892.en

Bograd SJ, Rabinovich AB, LeBlond PH, Shore JA (1997) Observations of seamount-attached eddies in the North 
Pacific. J Geophys Res Oceans 102:12441-12456

Bolnick DI, Svanbäck R, Fordyce JA, Yang LH, Davis JM, Hulsey CD, Forister ML (2003) The ecology of individuals: incidence and implications of individual specialization. Am Nat 161:1-28

Bortolotti GR, Marchant TA, Blas J, German T (2008) Corticosterone in feathers is a long-term, integrated measure of avian stress physiology. Funct Ecol 22:494-500

Bost CA, Cotté C, Bailleul F, Cherel Y and others (2009) The importance of oceanographic fronts to marine birds and mammals of the southern oceans. J Mar Syst 78:363-376

Breed GA, Bowen WD, McMillan JI, Leonard ML (2006) Sexual segregation of seasonal foraging habitats in a non-migratory marine mammal. Proc R Soc B 273: 2319-2326

B Brown ZW, van Dijken GL, Arrigo KR (2011) A reassessment of primary production and environmental change in the Bering Sea. J Geophys Res 116:C08014

Bunnefeld N, Börger L, van Moorter B, Rolandsen CM, Dettki H, Solberg EJ, Ericsson G (2011) A model-driven approach to quantify migration patterns: individual, regional and yearly differences. J Anim Ecol 80:466-476

Byrd GV, Schmutz JA, Renner HM (2008a) Contrasting population trends of piscivorous seabirds in the Pribilof Islands: a 30-year perspective. Deep-Sea Res II 55: 1846-1855

Byrd GV, Sydeman WJ, Renner HM, Minobe S (2008b) Responses of piscivorous seabirds at the Pribilof Islands to ocean climate. Deep-Sea Res II 55:1856-1867

Calenge C (2006) The package adehabitat for the R software: a tool for the analysis of space and habitat use by animals. Ecol Model 197:516-519

Cavalieri DJ, Parkinson CL, Gloersen P, Zwally HJ (1996) Sea ice concentrations from Nimbus-7 SMMR and DMSP SSM/I-SSMIS passive microwave data, Version 1. NASA National Snow and Ice Data Center Distributed Active Archive Center, Boulder, CO

Clavel J, Julliard R, Devictor V (2011) Worldwide decline of specialist species: toward a global functional homogenization? Front Ecol Environ 9:222-228

Colles A, Liow LH, Prinzing A (2009) Are specialists at risk under environmental change? Neoecological, paleoecological and phylogenetic approaches. Ecol Lett 12: 849-863

Conners MG, Hazen EL, Costa DP, Shaffer SA (2015) Shadowed by scale: subtle behavioral niche partitioning in two sympatric, tropical breeding albatross species. Mov Ecol 3:28

* Divoky GJ, Douglas DC, Stenhouse IJ (2016) Arctic sea ice a major determinant in Mandt's black guillemot movement and distribution during non-breeding season. Biol Lett 12:20160275

Elliott KH, Woo KJ, Gaston AJ (2009) Specialization in murres: the story of eight specialists. Waterbirds 32:491-506

Elliott KH, Chivers LS, Bessey L, Gaston AJ and others (2014) Windscapes shape seabird instantaneous energy costs but adult behavior buffers impact on offspring. Mov Ecol 2:17

Fieberg J, Kochanny CO (2005) Quantifying home-range overlap: the importance of the utilization distribution. J Wildl Manag 69:1346-1359

Flynn AJ, Williams A (2012) Lanternfish (Pisces: Myctophidae) biomass distribution and oceanographic-topographic associations at Macquarie Island, Southern Ocean. Mar Freshw Res 63:251-263

Gabrielson IN, Lincoln FC (1959) The birds of Alaska. Stackpole Co., Harrisburg, PA
Goutte A, Clément-Chastel C, Moe B, Bech C, Gabrielsen GW, Chastel O (2011) Experimentally reduced corticosterone release promotes early breeding in black-legged kittiwakes. J Exp Biol 214:2005-2013

* Goyert HF, Garton EO, Drummond BA, Renner HM (2017) Density dependence and changes in the carrying capacity of Alaskan seabird populations. Biol Conserv 209:178-187

Grebmeier JM, Overland JE, Moore SE, Farley EV and others (2006) A major ecosystem shift in the northern Bering Sea. Science 311:1461-1464

*Henson SA, Beaulieu C, Ilyina T, John JG and others (2017) Rapid emergence of climate change in environmental drivers of marine ecosystems. Nat Commun 8:14682

* Hindell MA, Bradshaw CJA, Sumner MD, Michael KJ, Burton HR (2003) Dispersal of female southern elephant seals and their prey consumption during the austral summer: relevance to management and oceanographic zones. J Appl Ecol 40:703-715

Hobson KA, Piatt JF, Pitocchelli J (1994) Using stable isotopes to determine seabird trophic relationships. J Anim Ecol 63:786

* Hückstädt LA, Burns JM, Koch PL, McDonald BI, Crocker DE, Costa DP (2012) Diet of a specialist in a changing environment: the crabeater seal along the western Antarctic Peninsula. Mar Ecol Prog Ser 455:287-301

* Jackson AL, Inger R, Parnell AC, Bearhop S (2011) Comparing isotopic niche widths among and within communities: SIBER - Stable Isotope Bayesian Ellipses in R. J Anim Ecol 80:595-602

Kitaysky AS, Kitaiskaia EV, Wingfield JC, Piatt JF (2001) Dietary restriction causes chronic elevation of corticosterone and enhances stress response in red-legged kittiwake chicks. J Comp Physiol B 171:701-709

Kitaysky AS, Piatt JF, Wingfield JC (2007) Stress hormones link food availability and population processes in seabirds. Mar Ecol Prog Ser 352:245-258

Kokubun N, Yamamoto T, Kikuchi DM, Kitaysky AS, Takahashi A (2015) Nocturnal foraging by red-legged kittiwakes, a surface feeding seabird that relies on deep water prey during reproduction. PLOS ONE 10:e0138850

Lascelles BG, Taylor PR, Miller MGR, Dias MP and others (2016) Applying global criteria to tracking data to define important areas for marine conservation. Divers Distrib 22:422-431

Lattin CR, Reed JM, DesRochers DW, Romero LM (2011) Elevated corticosterone in feathers correlates with corticosterone-induced decreased feather quality: a validation study. J Avian Biol 42:247-252

* Litzow MA, Mueter FJ, Hobday AJ (2014) Reassessing regime shifts in the North Pacific: incremental climate change and commercial fishing are necessary for explaining decadal-scale biological variability. Glob Change Biol 20:38-50

*Maxwell SM, Hazen EL, Bograd SJ, Halpern BS and others (2013) Cumulative human impacts on marine predators. Nat Commun 4:2688

* Merkel B, Phillips RA, Descamps S, Yoccoz NG, Moe B, Strøm H (2016) A probabilistic algorithm to process geolocation data. Mov Ecol 4:26

National Ice Center and National Snow and Ice Data Center (2010) Multisensor Analyzed Sea Ice Extent-Northern Hemisphere (MASIE-NH), Version 1. USA. National Snow and Ice Data Center, Boulder, CO

*Nelson BF, Daunt F, Monaghan P, Wanless S and others (2015) Protracted treatment with corticosterone reduces breeding success in a long-lived bird. Gen Comp Endocrinol 210:38-45 
Nordstrom CA, Battaile BC, Cotté C, Trites AW (2013) Foraging habitats of lactating northern fur seals are structured by thermocline depths and submesoscale fronts in the eastern Bering Sea. Deep-Sea Res II 88-89:78-96

Orben RA, Irons DB, Paredes R, Roby DD, Phillips RA, Shaffer SA (2015a) North or south? Niche separation of endemic red-legged kittiwakes and sympatric blacklegged kittiwakes during their non-breeding migrations. J Biogeogr 42:401-412

Orben RA, Paredes R, Roby DD, Irons DB, Shaffer SA (2015b) Wintering North Pacific black-legged kittiwakes balance spatial flexibility and consistency. Mov Ecol 3:36

Overland JE, Wang M, Wood KR, Percival DB, Bond NA (2012) Recent Bering Sea warm and cold events in a 95-year context. Deep-Sea Res II 65-70:6-13

* Paredes R, Harding AMA, Irons DB, Roby DD and others (2012) Proximity to multiple foraging habitats enhances seabirds' resilience to local food shortages. Mar Ecol Prog Ser 471:253-269

Paredes R, Orben RA, Suryan RM, Irons DB and others (2014) Foraging responses of black-legged kittiwakes to prolonged food-shortages around colonies on the Bering Sea shelf. PLOS ONE 9:e92520

* Pinchuk AI, Coyle KO, Farley EV, Renner HM (2013) Emergence of the Arctic Themisto libellula (Amphipoda: Hyperiidae) on the southeastern Bering Sea shelf as a result of the recent cooling, and its potential impact on the pelagic food web. ICES J Mar Sci 70:1244-1254

Quillfeldt P, McGill RAR, Furness RW, Möstl E, Ludynia K, Masello JF (2012) Impact of miniature geolocation loggers on a small petrel, the thin-billed prion Pachyptila belcheri. Mar Biol 159:1809-1816

R Core Development Team (2016) R: a language and environment for statistical computing. R Foundation for Statistical Computing, Vienna

Renner HM, Drummond BA, Benson AM, Paredes R (2014) Reproductive success of kittiwakes and murres in sequential stages of the nesting period: relationships with diet and oceanography. Deep-Sea Res II 109:251-265

Renner M, Salo S, Eisner LB, Ressler PH and others (2016) Timing of ice retreat alters seabird abundances and distributions in the southeast Bering Sea. Biol Lett 12: 20160276

Scales KL, Miller PI, Embling CB, Ingram SN, Pirotta E, Votier SC (2014) Mesoscale fronts as foraging habitats: composite front mapping reveals oceanographic drivers of habitat use for a pelagic seabird. J R Soc Interface 11: 20140679

Schultner J, Kitaysky AS, Welcker J, Hatch S (2013) Fat or lean: adjustment of endogenous energy stores to predictable and unpredictable changes in allostatic load. Funct Ecol 27:45-55

Shultz MT, Piatt JF, Harding AMA, Kettle AB, Van Pelt TI (2009) Timing of breeding and reproductive performance in murres and kittiwakes reflect mismatched seasonal prey dynamics. Mar Ecol Prog Ser 393:247-258

Shuntov VP (1974) Sea birds and the biological structure of the ocean. National Technical Information Service, Springfield, VA

Editorial responsibility: Rory Wilson, Swansea, UK
Siegel-Causey D, Meehan TE (1981) Red-legged kittiwakes forage in mixed-species flocks in southeastern Alaska. Wilson Bull 93:111-112

* Sinclair EH, Vlietstra LS, Johnson DS, Zeppelin TK and others (2008) Patterns in prey use among fur seals and seabirds in the Pribilof Islands. Deep-Sea Res II 55: 1897-1918

Smoker W, Pearcy WG (1970) Growth and reproduction of the lanternfish Stenobrachius leucopsarus. J Fish Res Board Can 27:1265-1275

Spitz DB, Hebblewhite M, Stephenson TR (2017) 'MigrateR': extending model-driven methods for classifying and quantifying animal movement behavior. Ecography 40: 788-799

* Springer AM, van Vliet GB (2014) Climate change, pink salmon, and the nexus between bottom-up and top-down forcing in the subarctic Pacific Ocean and Bering Sea. Proc Natl Acad Sci USA 111:E1880-E1888

Springer AM, McRoy CP, Flint MV (1996) The Bering Sea Green Belt: shelf-edge processes and ecosystem production. Fish Oceanogr 5:205-223

* Springer AM, Piatt JF, Shuntov VP, van Vliet GB, Vladimirov VL, Kuzin AE, Perlov AS (1999) Marine birds and mammals of the Pacific subarctic gyres. Prog Oceanogr 43:443-487

Stabeno PJ, Schumacher JD, Ohtani K (1999) The physical oceanography of the Bering Sea. In: Loughlin TR, Ohtani $\mathrm{K}$ (eds) Dynamics of the Bering Sea: a summary of physical, chemical, and biological characteristics, and a synopsis of research on the Bering Sea. AK-SG-99-03. University of Alaska Sea Grant Program, Fairbanks, AK, p 1-28

Stabeno PJ, Kachel DG, Kachel NB, Sullivan ME (2005) Observations from moorings in the Aleutian Passes: temperature, salinity and transport. Fish Oceanogr 14:39-54

Tanimata N, Yamamura O, Sakurai Y, Azumaya T (2005) Feeding habits and distribution of Stenobrachius leucopsarus (Myctophidae) in the central Bering Sea during late summer. North Pac Anadromous Fish Comm Tech Rep 6: $29-30$

* Thompson DR, Furness RW (1995) Stable-isotope ratios of carbon and nitrogen in feathers indicate seasonal dietary shifts in northern fulmars. Auk 112:493-498

Will AP, Suzuki Y, Elliott KH, Hatch SA, Watanuki Y, Kitaysky AS (2014) Feather corticosterone reveals developmental stress in seabirds. J Exp Biol 217:2371-2376

*Will AP, Kitaiskaia EV, Kitaysky AS (2018) Red-legged kittiwake feathers link food availability to environmental changes in the Bering Sea. Mar Ecol Prog Ser 593:261-274

Wood S, Scheipl F (2014) gamm4: Generalized additive mixed models using mgcv and lme4. $\mathrm{R}$ package version 0.2-3. http://CRAN.R-project.org/package =gamm4

Wyllie-Echeverria T, Wooster WS (1998) Year to-year variations in Bering Sea ice cover and some consequences for fish distributions. Fish Oceanogr 7:159-170

Kador S, Hunt GL Jr, TenBrink T, Aydin K (2013) Combined seabird indices show lagged relationships between environmental conditions and breeding activity. Mar Ecol Prog Ser 485:245-258

Submitted: July 3, 2017; Accepted: December 16, 2017 Proofs received from author(s): February 16, 2018 